\title{
A new chapter
}

\author{
Sally M. Marshall ${ }^{1}$
}

Published online: 26 October 2015

(C) Springer-Verlag Berlin Heidelberg 2015

This New Year brings with it a change of editorship for this most prestigious journal. For many years I have appreciated Diabetologia as a reader, author, reviewer and Associate Editor, and I am honoured now to take on the role of Editor-in-Chief.

Please allow me to introduce myself to those of you who do not know me yet. I am a proud Scot and stayed close to home to embark on an undergraduate clinical medical course at Glasgow University. After the first 2 years of the course I took the opportunity to study biochemistry (BSc, 1975) before returning to my medical studies. When I started working on the wards after 4 years of studying theory, suddenly, in front of me were people with the conditions I had learned about in textbooks. These people had meaningful, long-term connections with their physicians, and I relished the idea of building enduring relationships with those under my care. To find myself, in the third year of my medical degree, on a ward with the inspirational consultant diabetologist John Ireland was a lucky break - he instilled in me that a grasp of basic science is pivotal to clinical decision-making.

My background in biochemistry and metabolism led to an interest in understanding the pathophysiology of diabetes and how this affected clinical management, and so after my undergraduate medical education and junior doctor training in Glasgow, I decided to specialise in diabetes - a decision

Sally M. Marshall

sally.marshall@newcastle.ac.uk

1 Diabetes Research Group, Institute of Cellular Medicine, Faculty of Clinical Medical Sciences, Newcastle University, 4th Floor William Leech Building, Framlington Place, Newcastle upon Tyne NE2 4HH, UK that did not go down well with everyone. In an informal interview with the lead diabetes physician at Glasgow I was told: 'You're a woman - you've got to be a GP. Go and buy a cat and a rocking chair.' I realised that pursuing a career in diabetes was going to be harder than I'd first appreciated, but, undeterred, turned to John Ireland for advice. He recommended that I should do research, which I thought sounded like an excellent idea! A fortuitous meeting between John and previous Diabetologia Editor-in-Chief, George Alberti, led to me moving to Newcastle in 1982 to work in George's laboratory - the beginning of my research career and my particular passion for diabetic nephropathy.

It turned out that Newcastle was the place for me and I have been here ever since, with one break to widen my research horizons in Aarhus, Denmark, with Hans Ørskov and Allan Flyvbjerg. I now supervise a small but enthusiastic research group of my own that conducts clinical nephropathy studies and investigates links between nephropathy and cardiovascular disease. In addition to my research, I continue clinical diabetes work and general medical emergency and in-patient care. Just as I had hoped at the beginning of my medical career, now, in my position as Professor of Diabetes at the University of Newcastle and as an Honorary Consultant Physician, I have patients with diabetes whom I have known since I arrived in the city in 1982. I am proud to be able to pass on my expertise through roles outside the clinic and laboratory. I enjoy undergraduate and postgraduate medical and allied health professional teaching and am Newcastle University lead for the Integrated Academic Training Pathway. Currently, I chair the Diabetes UK development committee for Clinical Study Groups and am a member of the NIHR Efficacy and Mechanism Evaluation grant board. For the last 5 years I have been an Associate Editor of Diabetologia and prior to that I was Editor of Diabetic Medicine for 5 years. 
Having already successfully led one journal makes my new position no less challenging. To be responsible for a journal that has just celebrated its 50th birthday and to follow in the capable footsteps of 11 previous editors is a privilege. I would like to take this opportunity to pay tribute to my immediate predecessor and friend Juleen Zierath. Juleen is a clear-thinking, decisive visionary who has developed the journal in many ways during her term of office. Behind her she leaves a strengthened and celebrated journal, which I am delighted to take over. In her new position as President of the EASD I know that she will continue to offer support and guidance to all those associated with the journal. She has bequeathed me a talented and passionate group of Associate Editors and a dedicated and enthusiastic editorial office. With their support, working together with the EASD and our publisher Springer, I am confident that we can take Diabetologia to new heights.

One of my main aims is to bridge the gap between basic research and clinical care. Diabetologia has an advantage over some of its competitors because it is read by both basic scientists and clinicians. Maintaining and fostering this fusion is vitally important. It is becoming harder and harder for clinicians to keep abreast of the specialised basic research being undertaken and to understand what may be relevant in the clinical setting. I hope to help bridge this gap by commissioning translational review articles that describe the basic science behind exciting developments and discuss the clinical implications of these breakthroughs. I shall also work to attract submissions describing the end results of important clinical trials, an area that is currently under-represented.

I am keen to exploit technological advances to improve our readers' experience. We will be working with Springer to produce virtual special issues, grouping papers of interest to particular reader groups, to help ensure readers have easy access to articles that are likely to be of interest to them. In terms of social media, Diabetologia joined Twitter (@DiabetologiaJnl) last year and I hope more of you will join the conversation. Raising our profile and making our content accessible and more immediate brings benefits to authors and readers alike.

I will foster better links between the EASD Annual Meeting and Diabetologia. For example, this year will see publication of a new series of mini reviews derived from symposia sessions at the Annual Meeting. In addition, as ambassador for the journal, I will create dialogue across industry and reach out to more isolated researchers in areas such as Asia and South America.

These initiatives are, of course, on top of maintaining the timely processing of the $2000+$ papers submitted to the journal each year, each of which I will oversee personally.

So now it's time to 'keep the heid', as the Scots say, get on wi' it and look forward to the good times to come. 